\title{
O DIREITO DAS MINORIAS NA CONSTITUIÇÃO DA REPÚBLICA FEDERATIVA DO BRASIL DE 1988 E A SITUAÇÃO DOS ÍNDIOS ENQUANTO MINORIA ÉTNICA DO ESTADO BRASILEIRO*
}

\author{
Isete Evangelista Albuquerque ${ }^{* *}$
}

RESUMO : O presente artigo abordará o direito das minorias na Constituição da República Federativa do Brasil de 1988 e a situação dos índios enquanto minoria étnica do Estado Brasileiro, utilizando-se de uma metodologia de cunho qualitativa, exploratória e bibliográfica. No âmbito dos direitos humanos, o direito das minorias está presente nas discussões, principalmente sob a ótica do Estado Democrático de Direito, que assegura os ideais de justiça, dignidade e igualdade como valores supremos. Sabe-se que as minorias existem nas sociedades modernas, mas, ainda assim, acabam sendo marginalizadas socialmente e violadas em seus direitos de cidadania e democracia. Neste intento, os objetivos específicos a serem discutidos são: o Direito das Minorias como garantia da dignidade da pessoa humana; o papel do Estado Democrático de Direito na preservação do direito das minorias; e, por fim, a situação dos índios enquanto minoria étnica do Estado Brasileiro na Constituição Federal de 1988. Com efeito, os índios, um dos grupos sociais que contribuiu para o processo de miscigenação no Brasil, sofreram e, de certa forma, ainda sofrem discriminação racial. Percebe-se, pois que a sociedade brasileira, apesar do significativo avanço representado pela promulgação da Constituição Federal de 1988, não assimilou a dimensão da relevância do reconhecimento da diversidade étnicocultural, mormente a necessidade de conciliação entre o respeito à diversidade cultural de cada povo e a associação entre culturas sem o aniquilamento, por meio de uma cooperação recíproca. Por fim, deve-se respeitar a humanidade como um todo, para a promoção da justiça social, dignificar a condição de indígena enquanto minoria étnica e respeitar a sua liberdade e igualdade perante a sociedade dominante.

PALAVRAS-CHAVE: Direito das minorias. Valores supremos da Constituição. Estado Democrático de Direito. Índios.

\footnotetext{
* Artigo científico apresentado à disciplina Teoria da Constituição, ministrada pelo Prof. Rogério José Bento Soares do Nascimento, do Curso de Mestrado da Universidade Estácio de Sá. Mestre em Direito pela Pontifícia Universidade Católica do Rio de Janeiro (1990) e Doutor em Direito pela Universidade do Estado do Rio de Janeiro (2003).

** Mestranda em Direito pela Universidade Estácio de Sá e Prof.a do Curso de Direito da Faculdade Estácio da Amazônia de Boa Vista/Roraima. E-mail: isete-albuquerque@hotmail.com
} 


\section{THE RIGHT OF MINORITIES IN THE CONSTITUTION OF THE REPUBLIC OF BRAZIL AND THE SITUATION OF 1988 AS A MINORITY ETHNIC INDIANS OF THE BRAZILIAN STATE}

\section{ABSTRACT}

This article will address the rights of minorities in the Constitution of the Federative Republic of Brazil in 1988 and the situation of ethnic minority Indians while the Brazilian State, using a methodology die qualitative, exploratory and literature. In the context of human rights, the rights of minorities are present in the discussions, mainly from the perspective of the democratic rule of law, which ensures the ideals of justice, equality and dignity as supreme values. It is known that there are minorities in modern societies, but still end up being socially marginalized and violated in their rights of citizenship and democracy. In this aim, the specific objectives to be discussed are: the Right of Minorities to guarantee the dignity of the human person, the role of the democratic rule of law in preserving the rights of minorities, and, finally, the situation of the Indians as a minority ethnic State Brazilian Federal Constitution of 1988. Indeed, the indians, one of the social groups that contributed to the process of miscegenation in Brazil, suffered and somehow, still suffer racial discrimination. It can be seen therefore that the Brazilian society, despite the significant advance represented by the enactment of the 1988 Federal Constitution, not assimilated the dimension of the relevance of the recognition of ethno-cultural diversity, especially the need to reconcile respect for the cultural diversity of each association between people and cultures without the annihilation through mutual cooperation. Finally, one must respect the humanity as a whole, for the promotion of social justice, elevate the status of indigenous and ethnic minority while respecting their freedom and equality before the dominant society.

KEY-WORDS: Rights of minorities. Supreme values of the Constitution. Democratic State. Indians.

\section{INTRODUÇÃO}

A Constituição da República Federativa do Brasil de 1988, considerada uma constituição dirigente-programática-compromissória, ao instituir um Estado Democrático de Direito, destinou-se a assegurar direitos e garantias individuais, bem 
como valores supremos como justiça social, cidadania, dignidade da pessoa humana, igualdade, liberdade, visando a atender os anseios da sociedade contemporânea.

Neste contexto, o Estado Democrático de Direito tem como alguns dos seus objetivos fundamentais a construção de uma sociedade livre, justa e solidária, e a promoção de todos, sem preconceitos de origem, raça, sexo, cor, idade e quaisquer outras formas de discriminação.

Entretanto, os grupos sociais considerados distintos do grupo social dominante nem sempre logram o respeito e o tratamento da sociedade brasileira plural e democrática, pois, apesar de os mandamentos constitucionais consagrarem o direito das minorias étnicas no Brasil, ainda são marcantes os atos de preconceito racial e de discriminação. E Barbieri (2008, p. 29) complementa:

O exemplo mais evidente que nos salta os olhos, talvez seja a questão indígena e o esfacelamento de povos que vão à margem do dito processo da civilização dominante. Vemos o avanço de um novo século, e as mentalidades dominantes se negam em aceitar o direito das minorias, não só dos índios, como também dos negros, dos doentes, dos idosos etc.

Nesta seara, o presente trabalho analisará o direito das minorias na Constituição da República Federativa do Brasil de 1988 e a situação dos índios enquanto minoria étnica do Estado Brasileiro, especialmente a partir do reconhecimento da diversidade étnico-cultural pelos arts. $215^{1}$ e $231^{2}$ da Lei Maior.

A problemática cinge-se na discussão sobre o respeito aos direitos das minorias como um papel primordial do Estado Democrático de Direito, consagrado no texto constitucional, abordando, especificamente, o direito dos povos indígenas de serem índios e de permanecerem como tal, dotados de organização social, tradição, costumes, línguas, crenças, cultura.

\footnotetext{
${ }^{1}$ CRFB/1988, art. 215: “O Estado garantirá a todos o pleno exercício dos direitos culturais e acesso às fontes da cultura nacional, e apoiará e incentivará a valorização e a difusão das manifestações culturais".

${ }^{2}$ CRFB/1988, art. 231: "São reconhecidos aos índios sua organização social, costumes, línguas, crenças e tradições, e os direitos originários sobre as terras que tradicionalmente ocupam, competindo à União demarcá-las, proteger e fazer respeitar todos os seus bens".
} 
Oportuno destacar que, sob a égide da existência de uma sociedade democrática e pluralista, comprometida com a diferença, o multiculturalismo, a dignidade da pessoa humana, a liberdade e a igualdade frente a uma classe dominante, as minorias referem-se aos grupos sociais que se distinguem dos demais por serem considerados inferiores, sendo alvos de discriminação, preconceito social e não possuindo respeito aos seus direitos de cidadania (KOSOVSKI $\left.{ }^{3}, 2001\right)$.

É claro que uma sociedade considerada democrática e pluralista deve aceitar e aprender efetivamente a conviver com as diferenças existentes entre os mais diversos grupos sociais, de forma a promover a igualdade social de todos, afastando-os de qualquer preconceito e discriminação.

Portanto, a partir de 1988, com a promulgação da Constituição da República Federativa do Brasil, que proíbe qualquer tipo de discriminação, seja pela raça, etnia, religião, sexo ou outro fator distintivo da classe dita dominante, conferiu-se uma atenção mais especial à proteção dos direitos das minorias, garantindo-se o direito de ser diferente sem sofrer violação aos seus direitos de cidadania. Para tanto, deve-se efetivar a justiça social no Brasil.

Quanto aos índios, por serem cidadãos como todos os brasileiros, são merecedores de todos os direitos e garantias individuais, bem como valores supremos, consagrados no texto constitucional, já que, como bem preceitua o art. 5ำ, caput, da Constituição Federal de 1988, "todos são iguais perante a lei, sem distinção de qualquer natureza [...]". Por conseguinte, é imprescindível a proteção dos povos indígenas contra o preconceito étnico para a promoção da democracia racial.

\footnotetext{
${ }^{3}$ Kosovski (2009, p. 2) complementa afirmando ainda que “A história do Brasil está repleta de exemplos de grupos que foram escravizados, desprezados, renegados, isolados, explorados, ridicularizados e, como tais, tornados mais fáceis de serem controlados e dominados. O preconceito e a discriminação em relação às minorias fazem com que estas se sintam inferiores e lhes dê a sensação de que são incapazes, supérfluas e deslocadas".
} 


\section{O DIREITO DAS MINORIAS COMO GARANTIA DA DIGNIDADE DA PESSOA HUMANA}

No âmbito dos direitos humanos, o direito das minorias é uma realidade constante e presente nas discussões do Estado Brasileiro, haja vista a diversidade étnico-cultural que compõe a sociedade brasileira, diversidade esta reconhecida pelo Estado Democrático de Direito como expressão máxima da própria democracia e cidadania.

Oportuno destacar que o processo de formação e colonização do Brasil foi marcado pela miscigenação de, basicamente, três raças: índios, negros e brancos, acarretando o surgimento de um número considerável de minorias discriminadas, como frisam Groff e Pagel ${ }^{4}$ abaixo:

Destarte, aqueles países que tinham suas identidades culturais relativamente definidas difundiram-se com grupos culturais distintos, tanto por seus costumes, credos e religiões tanto quanto por suas diferenças biológicas. Por esse motivo, o Brasil é um exemplo dessa expansão cultural, pois, por volta do ano de 1500, passou a haver uma miscigenação de grupos culturais distintos, na medida em que os portugueses deram início à colonização do País. Isso trouxe sérias consequências, pois assistiu-se ao surgimento de identidades distintas e a uma tendência para a fragmentação cultural, bem como a um grande número de minorias discriminadas.

Assim, os grupos sociais excluídos, marginalizados, que se consideram ameaçados em seus direitos, devem tutelar a proteção dos mesmos como forma de garantir o respeito à dignidade da pessoa humana, inerente à própria condição de ser humano, sendo este um dos fundamentos da República Federativa do Brasil de 1988 (art. 1으, III, da CRFB).

Quanto aos objetivos fundamentais da República Federativa do Brasil, tem-se a erradicação da pobreza e da marginalização e a redução das desigualdades sociais e

\footnotetext{
${ }^{4}$ GROFF, Paulo Vargas; PAGEL, Rogério. Multiculturalismo: direito das minorias na era da globalização. Disponível em: $<$ http://www.google.com.br/url?sa=t\&rct=j\&q=multiculturalismo\%20e\%20diversidade\%20cultural\&sour ce $=$ web\&cd $=29 \& \mathrm{cad}=$ rja \&ved=0CFUQFjAIOBQ\&url=http\%3A\%2F\%2Fseer .uscs.edu.br\%2Findex . php $\% 2 \mathrm{Fr}$ evista_direito\%2Farticle\%2Fdownload\%2F862\%2F717\&ei=XGmaUJ7rJITY9QS4hoHIAw\&usg=AFQjCNHt9 ZSq2EOCfQiNDjxtqf5Zyw4F8g>. Acesso em: 14 nov. 2012.
} 
regionais (art. 3ㅇ, III, da CRFB); bem como a promoção do bem de todos, "sem preconceitos de origem, raça, sexo, cor, idade e quaisquer outras formas de discriminação" (art. 3ํ, IV, da CRFB). Portanto, são objetivos fundamentais que exigem uma ação do Estado e da sociedade como um todo em prol da transformação da realidade social do Estado Democrático de Direito.

De outro lado, as garantias constitucionais que asseguram o respeito às minorias e a concretização da igualdade substancial, que pressupõe o respeito às diferenças, sem qualquer forma de discriminação estão correlacionadas com a proteção da cultura brasileira, nos termos dos arts. 215 e 216 do texto constitucional, devendo ser interpretadas com base nos objetivos fundamentais da República Federativa do Brasil.

Já no âmbito das relações internacionais, reger-se-á, dentre aqueles elencados no art. 4음 da Constituição da República Federativa do Brasil de 1988, pelos princípios da prevalência dos direitos humanos, da autodeterminação dos povos, do repúdio ao racismo e da cooperação entre os povos para o progresso da humanidade.

Depreende-se, portanto, a partir da leitura destes dispositivos constitucionais, que o legislador constituinte reconheceu o direito das minorias, não se justificando qualquer ato de preconceito social e/ou discriminação, contrários à dignidade da pessoa humana e ao exercício da democracia social e aos direitos de cidadania.

Ademais, o preâmbulo da Constituição Federal de 1988 consagra os ideais de igualdade e justiça como "valores supremos de uma sociedade fraterna, pluralista e sem preconceitos [...]".

É de bom alvitre destacar que a cidadania deve ser compreendida como uma forma de preservar a dignidade como pessoa humana, fundada numa interação equitativa entre os cidadãos em seus direitos e deveres, para a plenitude da realização humana. Coadunando com o que ora fora exposto, Corrêa (2006, p. 217) define a cidadania como:

a realização democrática de uma sociedade, compartilhada por todos os indivíduos a ponto de garantir a todos o acesso ao espaço público e 
DOI 10.12957/rqi.2013.9311

condições de sobrevivência digna, tendo como valor-fonte a plenitude da vida. Isso exige organização e articulação política da população voltada para a superação da exclusão existente.

Deste modo, não se poderia aceitar a instituição de um Estado Democrático de Direito com a coexistência da exclusão social nem de qualquer forma de discriminação, sendo medida imperativa o respeito aos direitos das minorias, para a formação de uma sociedade brasileira democrática e multicultural.

\section{O PAPEL DO ESTADO DEMOCRÁTICO DE DIREITO NA PRESERVAÇÃO DO DIREITO DAS MINORIAS}

Ao discutir a noção de Estado Democrático de Direito, Barbieri (2008, p. 22) argumenta que:

[...] o Estado Democrático de Direito traria em seu conceito todo o ideário de justiça, igualdade e dignidade, com um mínimo normativo capaz de fundamentar os direitos e pretensões da sociedade e também de princípios, também formais do Estado de Direito que são: soberania, cidadania, Dignidade da Pessoa Humana, os valores sociais do trabalho e da livre iniciativa, o pluralismo político encartados no mandamento constitucional.

É oportuno ratificar que a construção do Estado Democrático de Direito, instituído na Constituição da República Federativa do Brasil de 1988, conferiu positividade jurídica às minorias étnicas no decorrer da aquisição de garantias e direitos fundamentais da pessoa humana.

Assim, considerando a aceitação da cultura e dos sistemas jurídicos particulares de cada povo como uma das características primordiais de um Estado Democrático de Direito, realidade esta que retrata o respeito à autodeterminação ${ }^{5}$ dos povos, Villares (2009, p. 24) destaca que:

\footnotetext{
${ }^{5}$ Imprescindível esclarecer que o direito à autodeterminação não deve ser compreendido como soberania, "[...] referindo-se a um grupo social ou a uma instituição que possui o direito de ditar suas próprias regras, dentro de um âmbito limitado de competência. Por essa razão, autonomia para os povos indígenas não se configura no equivalente à soberania, mas em seus direitos de pactuarem com o
} 
DOI 10.12957/rqi.2013.9311

O próprio Estado democrático, ao aceitar a cultura e os sistemas jurídicos particulares de cada povo que vive sob sua proteção, ganha legitimidade, não pela força, mas pela consciência dos cidadãos de se organizarem por regras que promovam o desenvolvimento e o progresso de todos, num processo de coesão e unificação do povo.

Ocorre que nem sempre houve a aceitação de sistemas jurídicos particulares de cada povo no Estado nacional. O Estado moderno, seguindo os legados do cristianismo, almejou a unidade da humanidade, buscando a imposição de uma mesma cultura, religião e educação para todos os povos que integrassem o mesmo território ${ }^{6}$.

Deste modo, "o Estado contemporâneo e seu Direito sempre negaram a possibilidade de convivência, num mesmo território, de sistemas jurídicos diversos, acreditando que o Direito estatal sob a cultura constitucional é único e onipresente" (SOUZA FILHO, 2009, p. 71).

Neste sentido, aduz Silveira (2010, p. 31) que "Comprimidos numa base territorial única, à mercê de um número étnico dominante e desprezados pelo estado que não enxerga as coletividades, essas minorias invisíveis sequer conseguem exercer o direito à autodeterminação de modo pacífico".

Portanto, os povos, identificados como minorias invisíveis, têm direito à autodeterminação, haja vista que coexistem dentro de um mesmo território estatal povos com línguas, crenças, costumes, tradições, culturas diferentes, sendo imprescindível o reconhecimento da pluralidade de culturas, que sempre existiu no interior de um único estado.

Há que se destacar que o reconhecimento da diferença e do direito das minorias contribui para a efetiva formação de uma sociedade brasileira democrática e multicultural.

estado as condições possibilitadoras e facilitadoras de sua sobrevivência e desenvolvimento enquanto povos, configurando um estado multicultural" (ALBUQUERQUE, 2008, p. 290).

${ }^{6}$ Souza Filho (2009, p. 64), ao relatar que, na prática, a integração revelou-se como uma discriminação, comenta que "a nova sociedade tirou dos indígenas tudo o que eles tinham, especialmente a sua identidade, para lhes oferecer uma integração que nem mesmo os brancos pobres, embebidos pela cultura burguesa logram conseguir". 
Argumenta Machado (2010, p. 159) que o multiculturalismo, enquanto movimento social que almeja proteger os direitos das minorias, "[...] orienta-se no sentido de gerar mudanças nas sociedades culturalmente plurais que se representam como homogêneas e uniculturais, construindo as subjetividades dos grupos culturalmente dominados".

Neste sentido, Albuquerque (2008, p. 14) afirma que "em sua origem o multiculturalismo surge como princípio ético orientador da ação de grupos étnicos que tiveram seus direitos de preservarem suas características culturais completamente negados".

Já Santos (2003, p. 26) explica que "a expressão multiculturalismo designa, originalmente, a coexistência de formas culturais ou de grupos caracterizados por culturas diferentes no seio das sociedades "modernas"”.

Sob a égide de um Estado Democrático de Direito, que busca a revalorização do direito, exige-se uma nova ordem jurídica contempladora dos anseios das minorias étnicas, atendendo-se às demandas sociais e aos conflitos inerentes ao Estado nacional heterogêneo e plural.

Quanto aos direitos culturais, Souza Filho (2009, p. 158-159) faz uma observação pertinente acerca da abrangência destes, defendendo que "os direitos culturais não são apenas os ligados ao respeito ao exercício de suas tradições, festas, alimentação, mais do que isso é o Direito a que as informações sobre o povo não seja recobertas por manto de preconceito, desprezo e mentiras".

Deste modo, a Constituição Federal de 1988, ao reconhecer a diversidade cultural aos diferentes grupos sociais e étnicos formadores da sociedade brasileira, segue a orientação do multiculturalismo (SANTILLI, 2005).

Neste sentido, o multiculturalismo, presente em diversos dispositivos constitucionais que tratam da proteção à cultura, refere-se à valorização da intensa diversidade cultural dos diferentes grupos sociais e étnicos, bem como ao reconhecimento do papel das manifestações culturais destes grupos para a formação da identidade cultural brasileira. 
DOI 10.12957/rqi.2013.9311

Ratificando a importância do reconhecimento do multiculturalismo, não só por se admitir as diferenças étnicas dos grupos sociais, mas também por se almejar a superação das injustiças decorrentes de um Estado homogêneo e unicultural, Albuquerque (2008, p. 211) argumenta que:

\begin{abstract}
Os povos indígenas constituem, atualmente, um referencial de agentes coletivos participativos de um novo marco democrático fundado na participação, diferença e igualdade dos povos. Trata-se de superar a ideia de um país monoétnico e unissocietário e assumir a realidade pluriétnica e multicultural, possibilitando as reais condições internas para os indígenas se beneficiarem dessa decisão, podendo, finalmente, viver de acordo com seus valores, crenças e instituições político-jurídicas. Direito à igualdade e à diferença definido em um referencial político-jurídico multicultural, no qual a diferença dá-se não como um privilégio, mas como uma permanente reivindicação.
\end{abstract}

Trata-se, pois, de uma sociedade brasileira democrática e plural comprometida com a diferença, o multiculturalismo, a dignidade da pessoa humana, a liberdade e a igualdade frente a uma maioria étnica.

\title{
A SITUAÇÃO DOS ÍNDIOS ENQUANTO MINORIA ÉTNICA DO ESTADO BRASILEIRO NA CONSTITUIÇÃO FEDERAL DE 1988
}

A partir da nova ordem jurídica brasileira, implementada pela Constituição da República Federativa do Brasil de 1988, não mais se admite a cogitação de uma política indigenista de integração dos povos indígenas como forma de imposição aos índios de terem que assimilar a cultura nacional. Neste sentido, Souza Filho (2009, p. 107) ratifica que:

A Constituição de 1988 reconhece aos índios o direito de ser índio, de manter-se como índio, com sua organização social, costumes, línguas, crenças e tradições. Além disso, reconhece o direito originário sobre as terras que tradicionalmente ocupam. Esta concepção é nova, e juridicamente revolucionária, porque rompe com a repetida visão integracionista. A partir de 5 de outubro de 1988, o índio, no Brasil, tem o direito de ser índio. 
DOI 10.12957/rqi.2013.9311

Portanto, o ordenamento jurídico brasileiro pós 1988 contemplou o direito de ser índio e de continuar sendo índio, e não restringindo o direito de ser índio a uma situação transitória tendente à integração à sociedade nacional.

O Tribunal Pleno do Supremo Tribunal Federal, em sede de Petição 3388/RR, cujo Relator foi o Ministro Carlos Ayres Britto, em 19 de março de 2009, ao decidir ação popular de demarcação da terra indígena Raposa Serra do Sol, explicou o significado do substantivo "índios" na Constituição Federal de 1988, que busca retratar uma diversidade indígena, como se vê no trecho da decisão jurisprudencial transcrito:

4. O SIGNIFICADO DO SUBSTANTIVO "ÍNDIOS" NA CONSTITUIÇÃO FEDERAL. O substantivo "índios" é usado pela Constituição Federal de 1988 por um modo invariavelmente plural, para exprimir a diferenciação dos aborígenes por numerosas etnias. Propósito constitucional de retratar uma diversidade indígena tanto interétnica quanto intra-étnica. Índios em processo de aculturação permanecem índios para o fim de proteção constitucional. Proteção constitucional que não se limita aos silvícolas, estes, sim, índios ainda em primitivo estádio de habitantes da selva. (Pet 3388 / RR RORAIMA; Relator(a): Min. CARLOS BRITTO; Julgamento: 19/03/2009; Órgão Julgador: Tribunal Pleno).

Oportuno frisar que, de acordo com a ementa jurisprudencial colacionada, temse que a Constituição Federal de 1988 concede proteção não só aos silvícolas ${ }^{7}$, que são os índios "primitivos ou selvagens", ainda habitantes da selva; mas também aos índios em processo de aculturação ${ }^{8}$, que não deixam de serem índios pela assimilação à comunidade nacional.

Intrigante a crítica construída por Cunha (apud BARRETO, 2008, p. 36) ao demonstrar que, erroneamente, há uma compreensão equivocada da sociedade brasileira acerca da definição do índio, argumentando que a própria lei não distingue índio de silvícola, como se todo índio tivesse que viver na selva, andar nu, ser

\footnotetext{
${ }^{7}$ Como observa Stefanini (2011, p. 27), “Não se pode ignorar que o termo silvícola, por imperativo histórico e semântico, como também por correspondência antropológica, entre outras, designa pessoas não aculturadas, ou melhor, pessoas isoladas, que vivem nas selvas ignotas em estágio evolutivo distinto dos demais brasilíndio; [...]. Todavia, tais concepções não se aperfeiçoam aos indígenas".

${ }^{8}$ Aculturação: s.f. 1. Fenômeno pelo qual um grupo de indivíduos de uma cultura definida entra em contato com uma cultura diferente e se adapta a ela ou dela retira elementos culturais. 2. Processo de absorção de ou adaptação a uma cultura, por parte de um indivíduo. 3. ACULTURAMENTO. Disponível em: <http://webdicionario.com/acultura\%C3\%A7\%C3\%A3o>. Acesso em: 14 nov. 2012.
} 
primitivo, de modo que o que o caracterizaria como índio seria a utilização de pinturas e tangas na selva.

Isto é resultante do fato de que, como bem destaca Barbieri (2008, p. 31), na verdade, "as imagens dos índios são contraditórias e fragmentadas na história que nos é contada, desde os bancos escolares".

Neste sentido, Silva (2011, p. 857-858) comenta que:

Os índios, como qualquer comunidade étnica, não param no tempo. A evolução pode ser mais rápida ou mais lenta, mas sempre haverá mudanças e, assim, a cultura indígena, como qualquer outra, é constantemente reproduzida, não igual a si mesma. Nenhuma cultura é isolada. Está sempre em contacto com outras formas culturais. A reprodução cultural não destrói a identidade cultural da comunidade, identidade que se mantém em resposta a outros grupos com os quais dita comunidade interage. Eventuais transformações decorrentes do viver e do conviver das comunidades não descaracterizam a identidade cultural.

De acordo com o texto colacionado, é imprescindível considerar que a sociedade como um todo, incluindo-se aqui os índios, evolui. Consequentemente, esta evolução natural revela a possibilidade lógica de os povos indígenas não permanecem culturalmente idênticos à imagem descrita quando do descobrimento do Brasil por Pêro Vaz de Caminha. Até porque, como mencionado acima, os traços culturais podem variar no tempo e no espaço, sem, contudo, interferir na identidade cultural.

O Estatuto do Índio, como é denominada a Lei no 6.001, de 19 de dezembro de 1973, dispõe sobre as relações do Estado brasileiro e da sociedade com os povos indígenas e continua em vigor até o momento, apesar de hoje ser "[...] visto com certo desconforto pelas organizações indígenas, por antropólogos, pelo movimento indigenista, por muitos juristas e pelo Estado. Mas, o Estatuto, à sua época, foi bastante avançado" (VILLARES, 2009, p. 63). Não mais se justifica, pois, a existência deste Estatuto por não mais corresponder aos anseios dos povos indígenas ${ }^{9}$.

\footnotetext{
${ }^{9}$ Santos (2003, p. 99-100) comenta que "com a promulgação da Constituição, as organizações indígenas e seus aliados começaram a se mobilizar para reescrever a lei geral, que deveria se chamar Estatuto dos Povos Indígenas, com conteúdo de direitos coletivos. Muitas versões foram escritas e muitas discussões realizadas. Uma versão consensual foi aprovada por uma Comissão do Congresso Nacional, mas por ordem direta do presidente da República eleito para o primeiro mandato, Fernando Henrique Cardoso,
} 
DOI 10.12957/rqi.2013.9311

Por conseguinte, procedendo-se a uma releitura do Estatuto do Índio com base na política indigenista vigente, qual seja, a valorização da heterogeneidade cultural, inúmeros são os dispositivos deste Estatuto incompatíveis com o ordenamento jurídico brasileiro vigente, como aduz Villares (2009, p. 62):

Os textos normativos presentes em alguns artigos do Estatuto do Índio estão eivados de inconstitucionalidades ou confrontantes com outras disposições legais infraconstitucionais, sendo por elas revogados ou tendo o jurista que interpretá-los para melhor extrair seu conteúdo normativo.

Verifica-se, portanto, que o Estado brasileiro passou a reconhecer a relatividade das culturas, assegurando direitos coletivos a povos indígenas e quilombolas. É o reconhecimento como povos culturalmente diferenciados, nos termos do art. $231^{10}$ da Constituição da República Federativa do Brasil, não mais prevalecendo o anseio à assimilação do índio pela comunidade nacional. É a denominada autodeterminação dos povos indígenas.

Pode-se ainda inferir que a aceitação da diversidade cultural encontra-se consagrada no art. $215^{11}$ do texto constitucional, de modo que se reconhecem os povos indígenas como tais, dotados de organização social, tradição, costumes, línguas, crenças, cultura, bem como se impõe ao Estado o dever de prestar proteção às culturas populares, indígenas e afro-brasileiras.

Assim, com a promulgação da Constituição da República Federativa do Brasil de 1988, inevitavelmente, o legislador constituinte conferiu um tratamento diferenciado e peculiar aos povos indígenas, reconhecendo-se a identidade cultural indígena, o direito de permanecerem como índios e o usufruto das terras tradicionalmente ocupadas por eles como direito originário.

foi tirada de pauta antes que ele tomasse posse, em dezembro de 1994. Desde então, por um estranho e não confessado interesse governamental, o Estatuto ficou numa espécie de "geladeira" legislativa".

${ }^{10}$ CRFB/1988, art. 231: "São reconhecidos aos índios sua organização social, costumes, línguas, crenças e tradições, e os direitos originários sobre as terras que tradicionalmente ocupam, competindo à União demarcá-las, proteger e fazer respeitar todos os seus bens".

${ }^{11}$ CRFB/1988, art. 215: "O Estado garantirá a todos o pleno exercício dos direitos culturais e acesso às fontes da cultura nacional, e apoiará e incentivará a valorização e a difusão das manifestações culturais". 
É de suma relevância mencionar que a Lei Maior, apesar do avanço do reconhecimento e da proteção da diversidade cultural, não traz em seu bojo qualquer definição de índio nem de comunidade indígena. Mas, ainda assim, representa o marco do rompimento da visão integracionista, reconhecendo-se o direito do índio de ser índio e de permanecer como tal.

Diante do reconhecimento e da proteção da diversidade cultural pela Constituição da República de 1988, bem como da superação do princípio integracionista insculpido no art. 1으 do Estatuto do Índio, este preceito estatutário deve ser considerado não recepcionado, pois a ordem constitucional vigente não mais promove a assimilação dos índios à cultura predominante entre os não-índios.

Depreende-se, a partir da análise transcrita, que, sob a égide da valorização da heterogeneidade cultural, ou o direito à diferença, instaurada pelo art. 231 da Constituição Federal de 1988, reconheceu-se o direito de ser índio (auto-identificação) e de permanecer nesta condição indígena (hetero-identificação), assegurando-se o direito à diferença.

Neste sentido, Barbieri (2008, p. 40) ressalta que: “o direito de ser índio deve ser, em primeiro lugar, o respeito ao seu direito à alteridade e à diferença. [...] A Carta Magna atual reconheceu aos povos indígenas o respeito à sua alteridade, defendendo a organização social, costumes, línguas, crenças e suas tradições".

$\mathrm{O}$ direito à alteridade refere-se ao direito de o índio ser diferente, levando ao entendimento de que a cultura dos não-índios não é a única forma de cultura válida. Já o direito à diferença, na compreensão de Barreto (2008, p. 105), “[...] não implica "homogeneidade", mas, ao contrário, "individualidade". No caso indígena, sobretudo, a diferença é condição mesma da própria identidade".

Destaca Barbosa (2001) que o grande dilema da humanidade é exatamente conciliar dois movimentos antagônicos: o respeito à diferença cultural e a associação entre culturas, sem, contudo, uma cultura aniquilar a outra, de modo a promover o progresso social por meio da cooperação/colaboração mútua. 
DOI 10.12957/rqi.2013.9311

Então, a nova ordem constitucional passou a garantir o respeito ao patrimônio cultural dos povos indígenas, seus valores artísticos e meios de expressão, não mais se pregando uma superioridade cultural dos "brancos" sobre os "índios".

Até porque não há que se falar em uma cultura superior a outra, pois todas são resultantes de vivências em contextos distintos, não se podendo estabelecer um parâmetro de comparativo justo a fim de determinar qualquer superioridade.

Nestes termos, o Estatuto do Índio, que representou um avanço à sua época, deve ser analisado com as devidas ressalvas, adaptando-se as suas disposições ao novo sistema constitucional implantado a partir de 1988, haja vista que vários dispositivos estatutários tornaram-se incompatíveis com os preceitos constitucionais ou foram por estes revogados tacitamente, devendo-se recorrer à interpretação conforme a constituição para a análise do caso concreto.

Por conseguinte, Villares (2008, p. 31) assevera que "o art. 3 da Lei 6.001/73 foi recepcionado pela Constituição Federal de 1988 e se coaduna integralmente com a Convenção 169 da OIT, não tendo sido revogado".

Ao tecer comentários acerca da evolução histórico-legislativa da questão indígena no Brasil, Rezende (2009, p. 30-31) assevera que:

As Constituições de 1934 e de 1937, no tocante aos silvícolas, limitaram-se a garantir-lhes a posse das terras que ocupam, vedando-Ihes a alienação.

[...]

A Carta de 1946 também se limitou a assegurar aos silvícolas a posse da terra que ocupam, e a de 1967, além disso, lhes garante o usufruto dos recursos naturais e de todas as utilidades nela existentes.

[...]

Em 1973 sobreveio a Lei 6.001, o Estatuto do Índio, cuja política exposta já no art. 10 é a de integrar, progressiva e harmoniosamente, o índio a comunhão nacional.

[...]

Por fim, a Constituição Federal de 1988 dedicou o capítulo VIII aos índios. Além de garantir os direitos originários às terras ocupadas, o art. 231 da Carta reconhece aos índios sua organização social, costumes, línguas, crenças e tradições.

Percebe-se que a proteção constitucional aos índios, momento em que ainda eram denominados de silvícolas, somente ocorreu, pela primeira vez, na Constituição Federal de 1934, inaugurando a fase da Constituição social, sob a influência da 
Constituição alemã de Weimar de 1939. É válido destacar que foi a primeira Constituição que tratou dos direitos dos povos indígenas, respeitando a posse de terra dos silvícolas e sendo da responsabilidade da União a promoção da política indigenista (SANTOS FILHO, 2006).

Por conseguinte, os textos constitucionais subsequentes (de 1937, 1946, $1967^{12}$ e sua Emenda Constitucional $\mathrm{n}$ 0 1/69) mantiveram a proteção aos silvícolas, avançando a Constituição Federal de 1988 na relação entre o Estado e os povos indígenas. Isto porque, dentre várias previsões, passou a denominar os índios de índios e conferiuIhes o direito de permanecerem como tal.

A Lei Maior trouxe, pois, um conjunto de normas jurídicas visando à efetiva proteção dos direitos e interesses dos índios, dedicando um capítulo especial aos índios, formado pelos arts. 231 e 232 deste diploma legal, além de contemplar diversos dispositivos protetivos dos índios (SILVA, 2011).

Assim, a partir da abordagem inovadora da Constituição da República Federativa do Brasil de 1988 sobre a temática dos direitos indígenas, passou-se a almejar uma aplicação dos dispositivos constitucionais com base em fundamentos novos, principalmente quando se trata de processos e situações envolvendo os indígenas, como destaca Barreto (2008, p. 25):

Neste sentido, a partir da Constituição de 1988 propugnamos para os "direitos indígenas" a substituição da atual "interpretação retrospectiva" por uma nova "interpretação prospectiva": isto é, uma interpretação calcada em novos fundamentos e voltada à consecução de novos objetivos.

Pode-se afirmar categoricamente que a Constituição de 1988 representou uma mudança de paradigma quanto aos direitos indígenas, tratando-os com merecedora

\footnotetext{
12 Importante mencionar que foi exatamente na vigência da Constituição de 1967 que houve, em substituição ao extinto Serviço de Proteção aos Índios - SPI, a criação da Fundação Nacional do Índio FUNAI, órgão do governo brasileiro que tem por finalidade "aplicar a política em prol do índio no território nacional; zelar pelo patrimônio indígena; fomentar estudos sobre populações indígenas que vivem em território brasileiro e garantir a proteção; demarcar, assegurar e proteger as terras tradicionalmente ocupadas pelos índios" (SANTOS FILHO, 2006, p. 43).
} 
extensão e profundidade comparadas às Constituições brasileiras anteriores, não mais fazendo referência à política de integração do índio à comunidade nacional.

Coadunando com as ideias ora esposadas, Barbieri (2008, p. 410) comenta que, após a Lei Maior, “[...] não falamos mais na política integracionista dizimadora, uma vez que os índios já não teriam que ser incorporados à comunhão nacional, forçosamente impingidos a assimilar nossa cultura, em detrimento da cultura indígena".

Diante deste novo paradigma jurídico sedimentado no texto constitucional, não mais merece prosperar a alegação de perda da identidade indígena pelo mero contato com outro grupo étnico, a partir da já superada ideia de serem os índios seres humanos com uma cultura inferior à da comunidade envolvente.

Não se pode negar que eventuais transformações culturais podem ocorrer naturalmente, mas tal fato não tem o condão de interferir na identidade cultural. Entretanto, constata-se que a identidade indígena fora, em diversos momentos históricos, usurpada forçosamente por meio da imposição da política integracionista anteriormente vigente na sociedade brasileira (VILLARES, 2009).

Verifica-se, então, que a situação dos índios, a partir da nova perspectiva constitucional, passou a ter um regime jurídico especial de proteção, em que estes não mais podem ser discriminados em categorias distintas de índios (isolados, em processo de integração e integrados), como estabelece o art. 4ㅇ do Estatuto do Índio, bem como não mais se reconhece a condição de indígena de forma transitória a ser assimilada pela sociedade nacional envolvente (SANTILLI, 2005).

Ademais, como preceitua o art. 5o, caput, da Constituição Federal de 1988, "todos são iguais perante a lei, sem distinção de qualquer natureza [...]", e os índios, por serem cidadãos como todos os brasileiros, são merecedores do desfrute de todos os direitos fundamentais arrolados no texto constitucional. Logo, é imprescindível a proteção destes povos indígenas contra o preconceito étnico.

Tanto é que o próprio art. 1으, caput, da Lei no 9.459, de 13 de maio de 1997 (que altera os arts. 1ㅇ e 20 da Lei no 7.716, de 5 de janeiro de 1989, que define os 
crimes resultantes de preconceito de raça ou de cor, e acrescenta parágrafo ao art. 140 do Decreto-lei no 2.848 , de 7 de dezembro de 1940), ao definir os crimes de racismo, elenca aqueles motivados por discriminação ou preconceito relativo à raça, cor, etnia, religião ou procedência nacional.

Deste modo, o Código Civil de 2002 (Lei no 10.406, de 10 de janeiro de 2002), sob a égide do reconhecimento da diversidade cultural, tão somente prevê, em seu art. 4ํㅡ, parágrafo único, que "a capacidade dos índios será regulada por legislação especial", atendendo aos preceitos constitucionais, que exigem uma proteção especial, e não restrição, aos direitos indígenas. Ao final desta explanação, conclui Barreto (2008, p. 43):

A CF/88 - que reconhece o índio como "diferente", sem que essa
"diferença" possa ser confundida com "incapacidade" e que reconhece a
"capacidade" do índio para ingressar em juízo na defesa de seus direitos,
sem depender da intermediação - alterou substancialmente a natureza do
regime tutelar indígena: primeiro, esse regime passou a ter natureza
exclusivamente "protetiva"; segundo, passou a ter estatura "constitucional".
Portanto, esta "proteção constitucional" está protegida de ataques pela via
do processo legislativo ordinário.

E à luz da Constituição Federal de 1988, em seu art. 232, ampliou-se o direito de ação do índio, das suas comunidades e organizações, bem como não há mais menção de participação do órgão de proteção ao índio - Fundação Nacional do Índio (FUNAI), conferindo-se aos indígenas plena capacidade civil e processual.

Com relação ao respeito à diferença e à alteridade, além do grande avanço trazido pelo art. 231 da Lei Maior, note-se que houve a contribuição da Convenção no 169 da Organização Internacional do Trabalho - OIT, que alterou o entendimento substituindo a Convenção no 107 de caráter integracionista à comunidade nacional, já que esta não invocou o direito à diferença.

No entendimento de Barbieri (2008, p. 44), por sua vez, a contribuição primordial da Convenção no 169 da OIT foi demonstrar a relevância da preservação da dignidade da pessoa humana do índio, estabelecendo "[...] os critérios de comunidade 
nacional e sobrevivência da cultura e diversidade indígena em todos os níveis, numa integração natural e progressiva".

Portanto, em uma sociedade democrática brasileira, os direitos indígenas previstos no art. 231 do texto constitucional, apesar de não elencados no rol do Título II intitulado como "Direitos e Garantias Fundamentais", devem ser compreendidos como direitos fundamentais, pois a finalidade da proteção constitucional do índio é exatamente respeitar a sua humanidade, dignificar a condição de indígena (minoria nacional) e respeitar a sua liberdade e igualdade perante a sociedade nacional (VILLARES, 2009).

\section{CONSIDERAÇÕES FINAIS}

Em um Estado Democrático de Direito, cujos ideários são justiça, igualdade e dignidade, é imprescindível a concretização destes valores constitucionais supremos para a construção de uma sociedade mais justa, democrática e sem preconceitos.

A seu turno, apesar da existência de um arcabouço constitucional de direitos e garantias individuais e da proibição a qualquer forma de discriminação, a sociedade brasileira, que proclama um discurso pluralista e democrático, precisa conscientizar-se da importância do efetivo respeito às minorias étnicas.

Os grupos sociais mais vulneráveis, como é o caso dos povos indígenas, são merecedores de uma proteção especial pelo Direito, como medida do reconhecimento da condição de ser humano, para só então falar-se em um verdadeiro Estado Democrático de Direito. Até porque a proteção das minorias é fundamental para o próprio exercício da democracia e da cidadania contempladas na Constituição Federal de 1988.

É de bom alvitre destacar que o direito das minorias é uma realidade presente nas discussões do Estado Brasileiro, já que o Brasil foi marcado por um processo de miscigenação de raças. Assim, não há como negar a existência de uma sociedade brasileira multiétnica e pluricultural, constituída por segmentos que compõem os 
grupos vulneráveis, diferenciando-se da classe dominante pelo fato de terem uma cultura própria, com organização social, crenças, costumes, tradições e línguas.

Por conseguinte, o reconhecimento da diversidade étnico-cultural aos povos indígenas pelo art. 231 do texto constitucional representou um significativo avanço para a construção de uma democracia mais inclusiva.

Deste modo, deve-se promover o bem de todos, sem qualquer tipo de preconceito ou discriminação, a fim de assegurar a concretização da igualdade substancial, dignidade da pessoa humana, cidadania e democracia.

\section{REFERÊNCIAS BIBLIOGRÁFICAS}

ALBUQUERQUE, Antonio Armando Ulian do Lago. Multiculturalismo e direito à autodeterminação dos povos indígenas. Porto Alegre: Sergio Antonio Fabris Editor, 2008.

BARBIERI, Samia Roges Jordy. Os direitos constitucionais dos índios e o direito à diferença, face ao princípio da dignidade da pessoa humana. Coimbra: Almedina, 2008.

BARBOSA, Marco Antonio. Direito antropológico e terras indígenas no Brasil. São Paulo: Plêiade, 2001.

BARRETO, Helder Girão. Direitos indígenas: vetores constitucionais. Curitiba: Juruá, 2003.

BRASIL. Constituição da República Federativa do Brasil de 1988. Disponível em: <http://www.planalto.gov.br/ccivil_03/Constituicao/Constituiçao.htm>. Acesso em: 14 nov. 2012.

Convenção no 107 da OIT, de 05 de junho de 1957. Concernente à proteção e integração das populações indígenas e outras populações tribais e semitribais de países independentes. Disponível em: <http://www.oas.org/dil/port/1957\%20Conven\%C3\%A7\%C3\%A30\%20sobre\%20Povos \%20Ind\%C3\%ADgenas\%20e\%20Tribais.\%20\%28Conven\%C3\%A7\%C3\%A30\%200IT\%20 n\%20\%C2\%BA\%20107\%29.pdf > Acesso em: 24 nov. 2012.

Decreto no 5.051, de 19 de abril de 2004. Promulga a Convenção no 169 da Organização Internacional do Trabalho - OIT sobre Povos Indígenas e Tribais. 
Disponível em: $\quad$ http://www.planalto.gov.br/ccivil 03/ ato20042006/2004/decreto/d5051.htm>. Acesso em: 24 nov. 2012.

Lei Federal $\mathbf{n}$ 0 6.001, de 19 de dezembro de 1973. Dispõe sobre O Estatuto do Índio. Disponível em: <http://www.planalto.gov.br/ccivil_03/Leis/L6001.htm>. Acesso em: 14 nov. 2012.

. Lei no 9.459, de 13 de maio de 1997. Altera os arts. 1 으 e 20 da Lei $n=7.716$, de 5 de janeiro de 1989, que define os crimes resultantes de preconceito de raça ou de cor, e acrescenta parágrafo ao art. 140 do Decreto-lei no 2.848, de 7 de dezembro de 1940. Disponível em: <http://www.planalto.gov.br/ccivil 03/Leis/L9459.htm>. Acesso em: 27 nov. 2012.

. Lei no 10.406, de 10 de janeiro de 2002. Institui o Código Civil. Disponível em: <http://www.planalto.gov.br/ccivil_03/leis/2002/L10406.ht>. Acesso em: 14 nov. 2012.

Supremo Tribunal Federal. AÇÃO POPULAR. DEMARCAÇÃO DA TERRA INDÍGENA RAPOSA SERRA DO SOL. INEXISTÊNCIA DE VÍCIOS NO PROCESSO ADMINISTRATIVO- DEMARCATÓRIO. OBSERVÂNCIA DOS ARTS. 231 E 232 DA CONSTITUIÇÃO FEDERAL, BEM COMO DA LEI № 6.001/73 E SEUS DECRETOS REGULAMENTARES. CONSTITUCIONALIDADE E LEGALIDADE DA PORTARIA № 534/2005, DO MINISTRO DA JUSTIÇA, ASSIM COMO DO DECRETO PRESIDENCIAL HOMOLOGATÓRIO. RECONHECIMENTO DA CONDIÇÃO INDÍGENA DA ÁREA DEMARCADA, EM SUA TOTALIDADE. MODELO CONTÍNUO DE DEMARCAÇÃO. CONSTITUCIONALIDADE. REVELAÇÃO DO REGIME CONSTITUCIONAL DE DEMARCAÇÃO DAS TERRAS INDÍGENAS. A CONSTITUIÇÃO FEDERAL COMO ESTATUTO JURÍDICO DA CAUSA INDÍGENA. A DEMARCAÇÃO DAS TERRAS INDÍGENAS COMO CAPÍTULO AVANÇADO DO CONSTITUCIONALISMO FRATERNAL. INCLUSÃO COMUNITÁRIA PELA VIA DA IDENTIDADE ÉTNICA. VOTO DO RELATOR QUE FAZ AGREGAR AOS RESPECTIVOS FUNDAMENTOS SALVAGUARDAS INSTITUCIONAIS DITADAS PELA SUPERLATIVA IMPORTÂNCIA HISTÓRICO-CULTURAL DA CAUSA. SALVAGUARDAS AMPLIADAS A PARTIR DE VOTO-VISTA DO MINISTRO MENEZES DIREITO E DESLOCADAS PARA A PARTE DISPOSITIVA DA DECISÃO. 1. AÇÃO NÃO CONHECIDA EM PARTE. Decisão em Petição Pet 3388 / RR - RORAIMA. Relator(a): Min. CARLOS BRITTO. Julgamento em: 19 mar. 2009.2 Disponível em: <http://www.stf.jus.br/portal/jurisprudencia/listarJurisprudencia.asp?s1=\%28\%EDndio \%29\&pagina=3\&base=baseAcordaos $>$. Acesso em: 24 nov. 2012.

CORRÊA, Darcisio. A construção da cidadania: reflexões histórico-políticas. 4. ed. ljuí: Unijuí, 2006.

DICIONÁRIO ON-LINE DE PORTUGUÊS. Disponível em: <http://webdicionario.com/acultura\%C3\%A7\%C3\%A3o>. Acesso em: 14 nov. 2012. 
GROFF, Paulo Vargas; PAGEL, Rogério. Multiculturalismo: direito das minorias na era da globalização. Disponível em: $<$ http://www.google.com.br/url?sa=t\&rct=j\&q=multiculturalismo\%20e\%20diversidade \%20cultural\&source=web\&cd=29\&cad=rja\&ved=0CFUQFjAIOBQ\&url=http\%3A\%2F\%2F seer.uscs.edu.br\%2Findex.php\%2Frevista_direito\%2Farticle\%2Fdownload\%2F862\%2F7 17\&ei=XGmaUJ7rJITY9QS4hoHIAw\&usg=AFQjCNHt9ZSq2EOCfQiNDjxtqf5Zyw4F8g>. Acesso em: 14 nov. 2012.

KOSOVSKI, Ester. Minorias e discriminação. In: SÉGUIN, Elida (Coord.). Direito das minorias. Rio de Janeiro, Forense, 2001.

MACHADO, Maria Costa Neves. Direito à diferença cultural. Curitiba: Juruá, 2010.

REZENDE, Guilherme Madi. Índio - tratamento jurídico-penal. Curitiba: Juruá, 2009.

SANTILLI, Juliana. Socioambientalismo e novos direitos: proteção jurídica à diversidade biológica e cultural. São Paulo: Peirópolis, 2005.

SANTOS, Boaventura de Sousa. Reconhecer para libertar: os caminhos do cosmopolitismo multicultural. Rio de Janeiro: Civilização Brasileira, 2003.

SANTOS FILHO, Roberto Lemos dos. Apontamentos sobre o direito indigenista. Curitiba: Juruá, 2006.

SILVA, José Afonso da. Curso de direito constitucional positivo. 34. ed. São Paulo: Malheiros Editores, 2011.

SILVEIRA, Edson Damas da. Meio ambiente, terras indígenas e defesa nacional: direitos fundamentais em tensão nas fronteiras da Amazônia brasileira. Curitiba: Juruá, 2010.

SOUZA FILHO, Carlos Frederico Marés. 0 renascer dos povos indígenas para o direito. Curitiba: Juruá, 2009.

STEFANINI, Luiz de Lima. Código indígena no direito brasileiro. Curitiba: Juruá, 201I. VILLARES, Luiz Fernando. Direito e povos indígenas. Curitiba: Juruá, 2009. 